\title{
Oesophageal cancer in Area 2 of Kwazulu-Natal: predictors of late presentation
}

\author{
Ferndale L, ${ }^{1,2}$ Sartorius B, ${ }^{3}$ Aldous C, ${ }^{2}$ Thomson SR ${ }^{4}$ \\ ${ }^{1}$ Department of Surgery, Greys Hospital, KwaZulu Natal, South Africa \\ ${ }^{2}$ School of Clinical Medicine, University of KwaZulu-Natal, Durban, KwaZulu-Natal, South Africa \\ ${ }^{3}$ Discipline of Public Health Medicine, School of Nursing and Public Health, University of KwaZulu-Natal, Durban, \\ South Africa \\ ${ }^{4}$ Division of Gastroenterology, Department of Medicine, University of Cape Town, South Africa
}

Corresponding author: Lucien Ferndale (lucienferndale@gmail.com)

\begin{abstract}
Background: There are limited prospective data sets on clinical characteristics, stage of presentation and treatment of patients with Oesophageal Squamous Cell Carcinoma (OSCC) in South Africa. This study aimed to assess the frequency and severity of clinical characteristics associated with late presentation of patients with OSCC presenting to a cancer referral centre in KwaZulu-Natal, South Africa.

Methods: A prospective consecutive series of patients presenting with confirmed OSCC treated at Greys Hospital in 2016/2017 were enrolled. Data collected included: age, gender, home language, referral centre, clinical and laboratory characteristics: dysphagia score, Eastern Cooperative Oncology Group (ECOG) performance status, body mass index (BMI), serum albumin, tumour pathology and treatment administered.

Results: One hundred patients were analysed. Ninety four percent spoke isiZulu. The mean age was 61 with a male to female ratio of 1.5:1 Ninety percent had palliative treatment as their overall assessment precluded curative treatment. Five patients underwent curative treatment. The age standardised incidence (ASR) was 25.2 per 100000 . The factors associated with late presentation and their frequency were: advanced dysphagia grade $(>/=2$ in $68 \%)$, malnutrition $\left(\mathrm{BMI}<18.5 \mathrm{~kg} / \mathrm{m}^{2}\right.$ in $49 \%$ ), hypoalbuminaemia (serum albumin $<35 \mathrm{~g} / 1$ in $70 \%$ ), poor performance status (ECOG $>/=2$ in $50 \%$ ) and moderate to poor tumour differentiation in $95 \%$ of patients.

Conclusions: OSCC in Kwazulu-Natal has double the ASR of South Africa and places a significant burden on the region's health care system. Factors associated with late presentation occur in the majority and alone or in combination preclude curative therapies. The frequency of these factors serve as a benchmark for comparison, and reduction in their frequency may indicate effectiveness of interventions designed to improve awareness and access to proper care.
\end{abstract}

S Afr J Surg 2019;57(2)

http://dx.doi.org/10.17159/2078-5151/2019/v57n2a2948

\section{Introduction}

Oesophageal cancer is the eighth most common cancer in the world. ${ }^{1}$ The highest incidence is reported in East and South-East Asia. Sub-Saharan Africa has the second highest incidence worldwide. ${ }^{1,2}$ The estimated Age Standardised Rate (ASR) in Southern Africa is 13.7 and 6.7 per 100000 in men and women respectively. ${ }^{1}$ Squamous cell carcinoma and adenocarcinoma are the two main histological subtypes. ${ }^{2}$ The former is the predominant subtype in South Africa where the Eastern Cape has the highest documented incidence. ${ }^{3-5}$ Oesophageal squamous cell carcinoma (OSCC) is generally associated with a poor prognosis. ${ }^{6}$ This is particularly true in South Africa where most patients with oesophageal cancer present late with debilitating symptoms and incurable disease. ${ }^{7,8}$ The majority of patients are not suitable for curative treatment at the time of diagnosis. ${ }^{69}$ This disease can have a devastating effect on quality of life and five-year survival is low. ${ }^{4,10}$

Retrospective studies provide limited information on the patient profile, clinical presentation and treatment of squamous cell carcinoma of the oesophagus in KwaZuluNatal (KZN). Many of these studies are based only on patients who reach health institutions and reflect the referral bias due to limited and regionally variable access to more sophisticated levels of care. Epidemiological studies are hampered by lack of awareness of the symptoms of the disease as well as the variable data sets coming from sub-Saharan Africa., ${ }^{1,11,12}$ Consequently it is probable that the incidence of oesophageal 


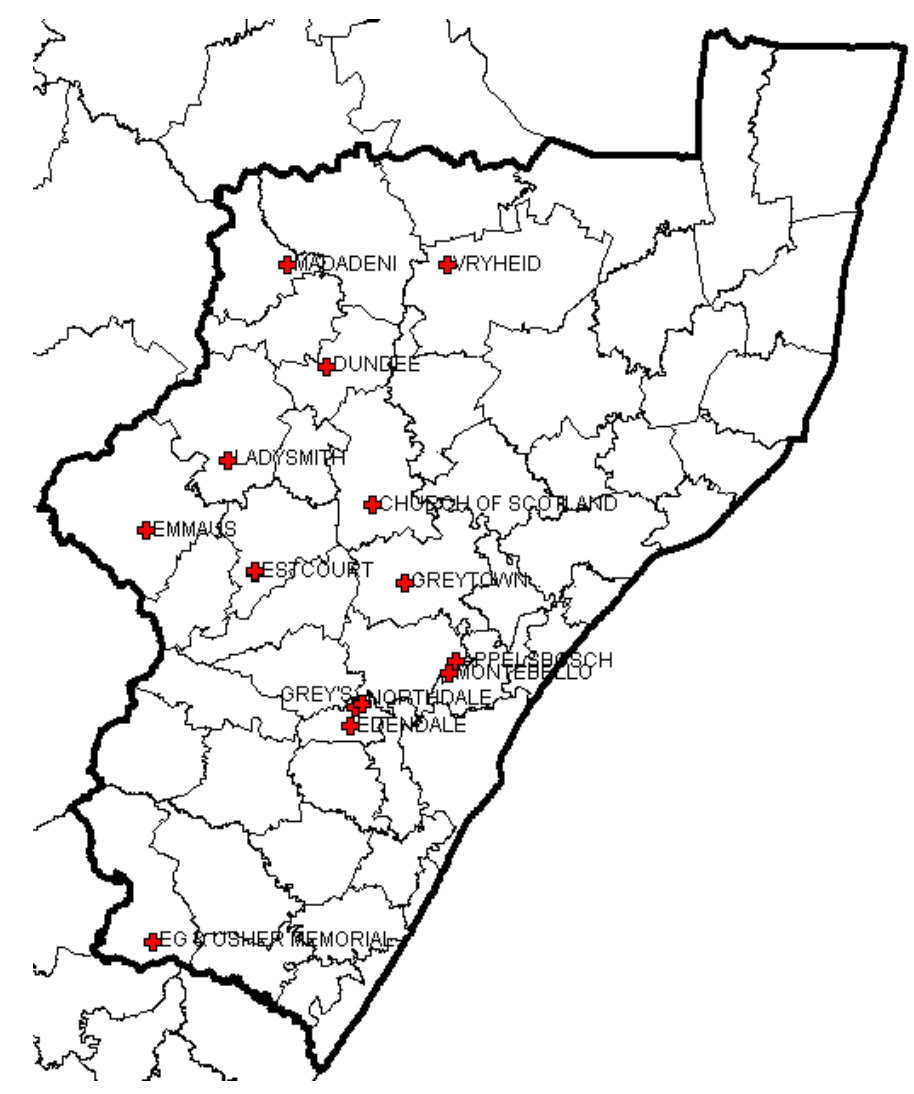

Figure 1. Referral centres from Area 2 (Greys catchment area)

squamous cell carcinoma may be underestimated in the region and that a lack of awareness of this disease may be contributing to the late presentation and poor prognosis.

To gain a better understanding of the clinical profile of patients diagnosed with OSCC and the frequency of factors associated with advanced disease at the time of diagnosis we prospectively collected and analysed data from patients presenting to a tertiary hospital in KZN.

\section{Methods}

\section{Study design}

This study employed a prospective case series design. All patients with a suspected or confirmed diagnosis of OSCC presenting to Greys Hospital between April 2016 and March 2017 were entered into the study. Greys hospital is a tertiary hospital in KZN providing care to patients from Area 2, which is a large area comprising urban and rural populations covering the western part of KZN, with a population of about three million and 20 referring hospitals. ${ }^{13,14}$ Data collected included demographic data, symptom severity, body mass index (BMI), serum albumin levels, performance status, tumour pathology and treatment administered. Significant weight loss was defined as weight loss resulting in a change in the size of the clothing they could wear comfortably. The BMI was defined as normal if it was between 18.5 and 25 . A BMI above 25 was classified as overweight and below 18.5 as underweight. A BMI of less than 16 was classified as severely underweight. Patients in whom the diagnosis of
OSCC could not be confirmed histologically were excluded from the analysis.

We assessed severity of dysphagia using the Mellow and Pinkas dysphagia score. ${ }^{15}$ This is a 5 -scale grading system where grade 0 denotes the ability to swallow normally: grade 1 dysphagia to normal solids, grade 2 dysphagia to soft solids, grade 3 dysphagia to liquids and solids and grade 4 inability to swallow saliva.

Performance status was measured using the Eastern Cooperative Oncology Group score ${ }^{16}$ as follows; Grade 0 - fully active with no physical restrictions; Grade 1 - some physical restriction but able to carry out light work; Grade 2 - ambulatory and capable of self-care but unable to carry out any work activity, confined to bed or wheelchair less than $50 \%$ of waking hours; Grade 3 - capable of only limited self-care, confined to bed or wheelchair for more than $50 \%$ of waking hours; Grade 4 - completely disabled, unable to carry out any self-care, totally confined to bed or chair.

A decision on whether to treat a patient palliatively or with curative intent was made based on a combination of clinical, pathological and imaging criteria. Criteria for palliative management were age $>70$ years, co-morbidities precluding major surgery, ECOG status $>1$, serum albumin $<25 \mathrm{~g} / \mathrm{l}$, tumour length $>8 \mathrm{~cm}$ or advanced tumour stage.

\section{Statistical analysis}

Data were processed and analysed using Stata 13.0 (StataCorp, 2013). Continuous variables were summarised using mean and standard deviation or median and interquartile range if evidence of skewing or asymmetrical outliers.

\section{Results}

\section{Demographics}

One hundred and eight patients were entered into the database over the study period. Eight patients were excluded from analysis: two had adenocarcinoma and six had no histological diagnosis. There were 59 males and 41 females and the mean age was 61 years $(\mathrm{SD}=12.8)$ The overall ASR $(95 \% \mathrm{CI})$ was 25.2 per 100 000. It was 29.1 in males and 17.2 in females. All patients were African with $94 \%$ first language isiZulu. The majority of patients $(70 \%)$ were referred from the three regional hospitals that fall within the drainage area of Greys hospital. The remainder of the referrals were equally distributed amongst the rural district hospitals and one patient was from outside area 2. The patient characteristics are summarised in Table 1.

\section{Clinical characteristics}

Clinical characteristics of the patient cohort are shown in Table 2. Of the 100 patients analysed, dysphagia was the primary presenting symptom in $97 \%$ of patients with $44 \%$ reporting grade 3 or 4 dysphagia. Sixty percent reported significant weight loss. BMI could be calculated in 94 patients. The median BMI was 20.0 (range 11-45) and $49 \%$ of patients had a low BMI at presentation. Furthermore, 19\% were severely underweight $\left(\right.$ BMI $\left.<16 \mathrm{~kg} / \mathrm{m}^{2}\right)$. The majority of patients 
Table 1: Cohort Characterisation

\begin{tabular}{lc}
\hline Characteristic & $\mathbf{N}=\mathbf{1 0 0}$ \\
\hline Mean age in years (range) & $61(32-93)$ \\
M:F & $1.5: 1$ \\
& $59: 41$ \\
\hline Race & \\
$\quad$ African & 100 \\
\hline Home language & \\
$\quad$ Zulu & 94 \\
$\quad$ English & 4 \\
$\quad$ Xhosa & 2 \\
\hline Level of referral centre & \\
Regional & 70 \\
District & 29 \\
Outside drainage area & 1
\end{tabular}

Table 2: Frequency of the clinical and biochemical assessment parameters

\begin{tabular}{|c|c|}
\hline Assessment parameter & Number \\
\hline Dysphagia score & $\mathbf{N}=\mathbf{1 0 0}$ \\
\hline 0 & 3 \\
\hline 1 & 29 \\
\hline 2 & 24 \\
\hline 3 & 36 \\
\hline 4 & 8 \\
\hline ECOG status & $\mathbf{N}=\mathbf{9 0}$ \\
\hline 0 & 4 \\
\hline 1 & 38 \\
\hline 2 & 27 \\
\hline 3 & 18 \\
\hline 4 & 3 \\
\hline Body Mass Index & $N=94$ \\
\hline Severely underweight $\left(<16 \mathrm{~kg} / \mathrm{m}^{2}\right)$ & 17 \\
\hline Underweight $\left(16-18.4 \mathrm{~kg} / \mathrm{m}^{2}\right)$ & 29 \\
\hline Normal $\left(18.5-24.9 \mathrm{~kg} / \mathrm{m}^{2}\right)$ & 34 \\
\hline Overweight ( $>/=25 \mathrm{~kg} / \mathrm{m} 2)$ & 14 \\
\hline Serum Albumin g/l & $\mathbf{N}=\mathbf{9 2}$ \\
\hline$<30$ & 40 \\
\hline $30-35$ & 25 \\
\hline$>35$ & 27 \\
\hline
\end{tabular}

(70\%) were hypoalbuminaemic (serum albumin $<35 \mathrm{~g} / \mathrm{l}$ ) at the time of presentation. The median serum albumin level was $30 \mathrm{~g} / 1$ (range 13-42). Only four out of 90 patients had a normal ECOG performance status, while $50 \%$ of patients had a performance status poorer than ECOG 1.
Table 3: Criteria for palliative management

\begin{tabular}{lc}
\hline Criterion for palliative management & Number of patients \\
\hline Age $>70$ years & 23 \\
Prohibitive co-morbidities & 5 \\
Serum Albumin $<25 \mathrm{~g} / 1$ & 17 \\
ECOG $>/=2$ & 48 \\
Tumour length $>8 \mathrm{~cm}$ & 37 \\
Advanced tumour stage & 4
\end{tabular}

Table 4: Frequency of indicators of late presentation

\begin{tabular}{lc}
\hline Indicator & Percentage of patients \\
\hline Dysphagia grade $>/=2$ & 68 \\
$\mathrm{BMI}</=18.5$ & 53 \\
Serum Albumin $<35 \mathrm{~g} / 1$ & 70 \\
$\mathrm{ECOG}>/=2$ & 50 \\
Degree of tumour differentiation - & 92 \\
Moderate to severe &
\end{tabular}

\section{Pathology and treatment}

The mean tumour length was $6.4 \mathrm{~cm}(\mathrm{SD}=3.5)$ and the majority $(72 \%)$ were moderately differentiated with only $8 \%$ being well-differentiated. Ninety percent of patients were treated palliatively. Five percent were treated surgically and five percent declined treatment, could not be palliated or were lost to follow-up. Self-expanding metal stents (SEMS) were inserted in 82 of 90 patients selected for palliative treatment. The other forms of palliation used included chemoradiotherapy in two patients and serial oesophageal dilatation in six. Details of patients that fulfilled the criteria for palliative management are shown in Table 3. A number of patients had more than one indication for palliative management.

The factors that indicate a late presentation and their frequencies are shown in Table 4.

\section{Discussion}

Our study indicates that OSCC is a significant health care problem in KwaZulu-Natal. The fact that all of the 100 patients collected over a one-year period were African underscores the burden this disease puts on this particular population group. Our ASR of 25 is higher than the recorded incidence in South Africa, ${ }^{17}$ indicating that the disease may be under-reported nationally. The mean age of 61 years is in keeping with reports in the published literature. Our male to female ratio of 1.5:1 also shows a similar male preponderance to other regions of Africa (1.6:1) but much lower than the 3:1 ratio reported from other regions of the world. ${ }^{1,8,18}$

We have identified a number of factors that are associated with late presentation and diagnosis at an advanced stage, which is a world-wide problem, but seems to be a particular problem in our patient population. ${ }^{19,20,21}$ Dysphagia indicates a more advanced T-stage of oesophageal cancer. ${ }^{21,22,23}$ The 


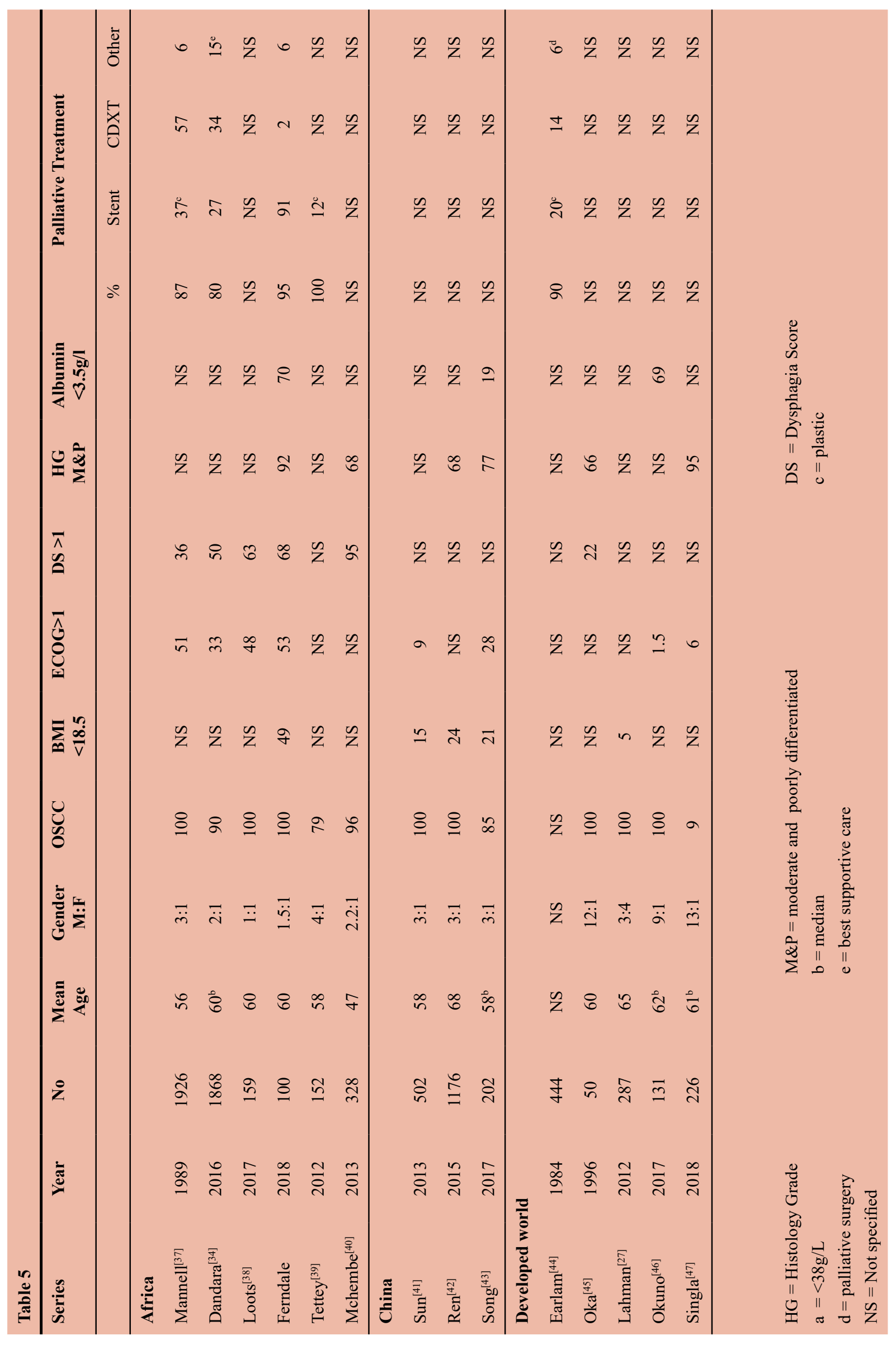


prevalence of dysphagia (97\%) and advanced grade (44\% with grade 3 or 4 dysphagia) was particularly striking. Secondly, a history of weight loss, low body mass index and low serum albumin, factors often used in combination to identify patients with malnutrition, were present in the majority of our patients. ${ }^{24} \mathrm{~A}$ low BMI has been shown to have a negative impact on survival and may even increase the risk of developing OSCC. ${ }^{25,26,27}$ These paramaters, alone or in combination, also impact on prognosis, and predict response to chemo-radiotherapy. ${ }^{28,29,30}$ Thirdly, patients with an ECOG status 0 made up only $4 \%$ of the cohort, a proportion much lower than reported in the literature. ${ }^{31}$ The last indicator of late presentation among our patients is the degree of differentiation on pathological assessment. The degree of differentiation has been shown to be a risk factor for poor prognosis at an advanced stage $e^{32,33}$ and more than $80 \%$ of our patients had moderately to poorly differentiated tumours.

The abovementioned factors culminated in only $5 \%$ of patients in our series being offered potentially curative treatment, a figure much lower than reported by others. ${ }^{6,34}$ In the context, it is reassuring that placement of self-expanding metal stent which is considered the standard of care in palliation of dysphagia was available and could be performed in $90 \%$ of patients who were palliated..$^{35,36}$ Table 5 highlights the paucity and variability of data points we have identified as indicators of late presentation in oesophageal cancer in other series.

The drivers of late presentation in our patient population need further investigation. Some patients seek help from traditional healers before presenting to hospital, with socioeconomic factors given as the main reason given by the remainder. ${ }^{7}$ Whereas patients factors are a major contributor to delay, the lack of knowledge among health care workers and lack of clear care pathways in the health care system probably also contribute to delay in diagnosis and treatment. These factors need to be quantified in order to devise strategies to address the problem.

\section{Conclusion}

Our data show a higher incidence of oesophageal cancer than expected and that patients with oesophageal cancer in our population have a poorer prognosis than patients with the same diagnosis elsewhere. Potential interventions to improve outcomes are population and health care worker education particularly around the recognition of dysphagia as an alarm symptom and the need for urgent endoscopic evaluation. This would include streamlining of referral patterns and monitoring times from presentation to diagnosis, assessment and treatment. Implementation would require a coordinated research agenda not simply addressing health systems research but also epidemiological and basic science approaches to better understand the diseases aetiopathogenesis with a view to the possible introduction of screening strategies.

The study was approved by the Biomedical Research Ethics Committee of University of KwaZulu-Natal (ref. no. BF270/15).

\section{REFERENCES}

1. Ferlay J, Soerjomataram I, Dikshit R, et al. Cancer incidence and mortality worldwide: Sources, methods and major patterns in GLOBOCAN 2012. Int J Cancer. 2015;136(5):E359-E386. doi: 10.1002/ijc. 29210

2. Torre LA, Siegel RL, Ward EM, Jemal A. Global Cancer Incidence and Mortality Rates and Trends-An Update. Cancer Epidemiol Biomarkers Prev. 2016;25(1):16-27. doi: 10.1158/1055-9965.EPI-15-0578

3. Pickens A, Orringer MB. Geographical distribution and racial disparity in esophageal cancer. Ann Thorac Surg. 2003;76(4):S1367-S1369.

4. Hendricks D. Parker MI. Oesophageal Cancer in Africa. IUBMB Life. 2002;53(4-5):263-268. doi:10.1080/15216540290099043

5. Parkin DM, Bray F, Ferlay J, Jemal A. Cancer in Africa 2012. Cancer Epidemiol Biomarkers Prev. 2014;23(6):953-966. doi: 10.1158/1055-9965.EPI-14-0281

6. Zhang Y. Epidemiology of esophageal cancer. World J Gastroenterol. 2013 Sep 14;19(34):5598-606. doi: 10.3748/wjg. v19.i34.5598

7. Govender M, Ferndale L, Clark D. Oesophageal cancer in South Africa: The long timeline from onset of symptoms to definitive management. S Afr J Oncol. 2017;1(0),a6. Available from: https://doi.org/10.4102/sajo.v1i0.6.

8. Kachala R. Systematic review: epidemiology of Oesophageal Cancer in SubSaharan Africa. Malawi Med J. 2010;22(3):65-70.

9. Gerdes H, Ferguson M. Palliation of Esophageal Cancer. In Posner M, Vokes E, Weichselbaum R. American Cancer Society. Atlas of Clinical Oncology. Cancer of the upper gastrointestinal tract: BC Decker Inc; 2002. p. 184-204.

10. Besharat S, Jabbari A, Semnani S, Keshtkar A, Marjani J. Inoperable esophageal cancer and outcome of palliative care. World J Gastroenterol. 2008;14(23):3725-8.

11. Pacella-Norman R, Urban M, Sitas F, et al. Risk factors for oesophageal, lung, oral and laryngeal cancers in black South Africans. Br J Cancer. 2002 Jun 5;86(11):1751-6. doi: 10.1038/ sj.bjc. 6600338

12. Loots E, Sartorius B, Madiba T, Mulder C, Clark D. Is Clinical Research in Oesophageal Cancer in South Africa in Crisis? A Systematic Review. World J Surg. 2017;41(3):810-6. doi: 10.1007/s00268-016-3778-5

13. Caldwell R, Gaede B, Aldous C. Description of an internal medicine outreach consultant appointment in western KwaZulu-Natal, South Africa, 2007 to mid-2014. S Afr Med J. 2015;105(5):353-6. doi: 10.7196/samj.9173

14. Statistics South Africa. Census 2011. Provincial profile: KwaZulu-Natal. Available from: www.statssa.gov.za.

15. Mellow M, Pinkas H. Endoscopic laser therapy for malignancies affecting the esophagus and gastroesophageal junction. Arch Intern Med. 1985 Aug;145:1443-6.

16. Oken MM, Creech RH, Tormey DC, et al. Toxicity and response criteria of the Eastern Cooperative Oncology Group. Am J Clin Oncol. 1982 Dec;5(6):649-55.

17. Fitzmaurice C, Allan C, Barber R, et al. Global, Regional, and National Cancer Incidence, Mortality, Years of Life Lost, Years Lived With Disability, and Disability-Adjusted Life-years for 32 Cancer Groups, 1990 to 2015: A Systematic Analysis for the Global Burden of Disease Study. JAMA Oncol. $2017 \mathrm{Apr}$ 1;3(4):524-48. doi: 10.1001/jamaoncol.2016.5688.

18. Ferlay J, Shin H, Bray F, et al. Estimates of worldwide burden of cancer in 2008: GLOBOCAN 2008. Int J Cancer. 2010;127(12):2893-917. doi: 10.1002/ijc.25516.

19. Bird-Lieberman, Fitzgerald R. Early diagnosis of oesophageal 
cancer. $\mathrm{Br} \mathrm{J}$ Cancer. 2009; 101(1):1-6. doi: 10.1038/ sj.bjc. 6605126

20. Nun-Anan P, Vilaichone RK. Late stage and grave prognosis of esophageal cancer in Thailand. Asian Pac J Cancer Prev. 2015;16(5):1747-9.

21. Lin S, Chang J. Esophageal cancer: diagnosis and management. Chin J Cancer. 2010;29(10):843-54.

22. Layke J, Lopez P. Esophageal cancer: a review and update. Am Fam Physician. 2006;73(12):2187-94.

23. Ripley RT, Sarkaria IS, Grosser R, et al. Pretreatment Dysphagia in Esophageal Cancer Patients May Eliminate the Need for Staging by Endoscopic Ultrasonography. Ann Thorac Surg. 2016;101(1):226-30. doi: 10.1016/j.athoracsur.2015.06.062

24. Meuller C, Compher C, Ellen D, American Society for Parenteral and Enteral Nutrition (A.S.P.E.N.) Board of Directors. JPEN J Parenter Enteral Nutr. 2011;35(1):16-24. doi: $10.1177 / 0148607110389335$

25. Tretli S, Robsahm TE. Height, weight and cancer of the oesophagus and stomach: a follow-up study in Norway. Eur J Cancer Prev. 1999 Apr;8(2):115-22.

26. Johnson I. Understanding the association between diet and nutrition in upper gastrointestinal cancer. Expert Rev Gastroenterol Hepatol. 2015;9(11):1347-9. doi: 10.1586/17474124.2015.1088383

27. Lahmann P, Pandeya N, Webb P, et al. Body mass index, longterm weight change, and esophageal squamous cell carcinoma: is the inverse association modified by smoking status? Cancer. 2012 Apr 1;118(7):1901-9. doi: 10.1002/cncr.26455

28. Heys S. Walker L, Deehan D, Eremin O. Serum albumin: a prognostic indicator in patients with colorectal cancer. J R Coll Surg Edinb. 1998;43(3):163-8.

29. Gupta D, Lis C. Pretreatment serum albumin as a predictor of cancer survival: A systematic review of the epidemiological literature. Nutr J. 2010;9:69-84. doi: 10.1186/1475-2891-9-69

30. Di Fiore F, Lecleire S, Pop D, et al. Baseline nutritional status is predictive of response to treatment and survival in patients treated by definitive chemoradiotherapy for a locally advanced esophageal cancer. Am J Gastroenterol. 2007;102(11):2557-63.

31. Rice TW, Apperson-Hansen C, DiPaola LM, et al. Worldwide Esophageal Cancer Collaboration: clinical staging data. Dis Esophagus. 2016 Oct;29(7):707-14. doi: 10.1111/dote.12493

32. Pauthner M, Haist T, Mann M, et al. Surgical Therapy of Early Carcinoma of the Esophagus. Viszeralmedizin. 2015 Oct;31(5):326-30. doi: 10.1159/000441049

33. Seoane-Romero JM, Vázquez-Mahía I, Seoane J, Factors related to late stage diagnosis of oral squamous cell carcinoma. Med Oral Patol Oral Cir Bucal. 2012 Jan 1;17(1):e35-40.

34. Dandara C, Robertson B, Dzobo k, Moodley L, Parker I. Patient and tumour characteristics as prognostic markers for oesophageal cancer: a retrospective analysis of a cohort of patients at Groote Schuur Hospital. Eur J Cardiothorac Surg. 2016 Feb;49(2):629-34. doi: 10.1093/ejcts/ezv135
35. Diamantis G, Scarpa M, Bocus P, et al. Quality of life in patients with esophageal stenting for the palliation of malignant dysphagia. World J Gastroenterol. 2011;17(2):144-50. doi: 10.3748/wjg.v17.i2.144

36. Dai $\mathrm{Y}, \mathrm{Li} \mathrm{C}, \mathrm{Xie} \mathrm{Y}$, et al. Interventions for dysphagia in oesophageal cancer. Cochrane Database Syst Rev. 2014;(10):CD005048. doi: 10.1002/14651858.CD005048.pub4

37. Mannell A, Murray W. Oesophageal cancer in South Africa. A review of 1926 cases. Cancer. 1989 Dec 15;64(12):2604-8.

38. Loots E, Sartorius B, Madiba TE, et al. Oesophageal squamous cell cancer in a South African tertiary hospital: a risk factor and presentation analysis. S Afr J Surg. 2017 Sep;55(3):42-6.

39. Tettey M, Edwin F, Aniteye E, et al. The changing epidemiology of esophageal cancer in sub-Saharan Africa - the case of Ghana. Pan Afr Med J. 2012;13:6. Epub 2012 Sep 7.

40. McHembe MD, Rambau PF, Chalya PL, et al. Endoscopic and clinicopathological patterns of esophageal cancer in Tanzania: experiences from two tertiary health institutions. World J Surg Oncol. 2013 Oct 4;11:257. doi: 10.1186/1477-7819-11-257

41. Sun P, Zhang F, Chen C, et al. Comparison of the prognostic values of various nutritional parameters in patients with esophageal squamous cell carcinoma from Southern China. J Thorac Dis. 2013 Aug;5(4):484-91. doi: 10.3978/j.issn.20721439.2013.08.38

42. Ren C, Cai XY, Qiu MZ, et al. Impact of body mass index on survival of esophageal squamous carcinoma patients in southern China. J Thorac Dis. 2015 Mar;7(3):337-45. doi: 10.3978/j. issn.2072-1439.2014.10.12

43. Song T, Wan Q, Yu W, et al. Pretreatment nutritional risk scores and performance status are prognostic factors in esophageal cancer patients treated with definitive chemoradiotherapy. Oncotarget. 2017 Oct 19;8(58):98974-84. doi: 10.18632/ oncotarget. 21940

44. Earlam R. Oesophageal cancer treatment in North East Thames region, 1981: medical audit using Hospital Activity Analysis data. Br Med J (Clin Res Ed). 1984 Jun 23;288(6434):1892-4.

45. Oka M, Yamamoto K, Takahashi M, et al. Relationship between serum levels of interleukin 6, various disease parameters and malnutrition in patients with esophageal squamous cell carcinoma. Cancer Res. 1996 Jun 15;56(12):2776-80.

46. Okuno T, Wakabayashi M, Kato K, et al. Esophageal stenosis and the Glasgow Prognostic Score as independent factors of poor prognosis for patients with locally advanced unresectable esophageal cancer treated with chemoradiotherapy (exploratory analysis of JCOG0303). Int J Clin Oncol. 2017 Dec;22(6):10421049. doi: 10.1007/s10147-017-1154-6

47. Singla S, Gabriel E, Alnaji R, et al. Complete pathologic response is independent of the timing of esophagectomy following neoadjuvant chemoradiation for esophageal cancer. J Gastrointest Oncol. 2018 Feb;9(1):73-9. doi: 10.21037/ jgo.2017.09.11 